\title{
PENERAPAN SISTEM PENDUKUNG KEPUTUSAN DALAM PEMILIHAN ANAK BERPRESTASI TINGKAT AUTIS DENGAN METODE ELECTRE
}

\author{
Dewi Wahyuni \\ Universitas Imelda Medan \\ Medan, Indonesia \\ dhewiqchan@gmail.com
}

\begin{abstract}
Abstrak
Yayasan Ananda Karsa Mandiri Medan merupakan tingkat pendidikan yang diperuntukkan bagi anak berkebutuhan khusus (ABK), memiliki peranan sangat penting dalam mengembangkan kepribadian anak melalui kecerdasan yang dimiliki agar nanti nya mereka dapat dipersiapkan untuk memasuki jenjang pendidikan berikutnya. Sekolah anak autis ini merupakan lembaga pendidikan khusus diselenggarakan bagi peserta didik yang memasuki usia antara 6-12 tahun dengan memiliki tingkat kecerdasan luar biasa dan tersedia pada tingkat pendidikan dasar dan menengah. Anak autis pada usia 6-12 tahun ini umumnya memiliki masalah pada perilaku non normatif yang dapat dilihat dari tingkat perkembangannya yaitu mengalami kesulitan dalam penyesuaian diri ketika belajar (tidak konsentrasi) maupun dalam beraktivitas pada lingkungan sosialnya baik disekolah atau dirumah. Agar dapat diketahui dengan pasti apakah anak autis ini dapat berprestasi atau tidak di sekolah nya, maka terdapat beberapa kriteria tertentu yang perlu dipahami oleh pendidik dalam memberikan penilaian mencakup segala aspek melalui penggunaan metode electre. Metode electre merupakan salah satu metode dengan menentukan urutan serta menghasilkan keputusan dari berbagai alternatif dalam MCDM (Multi Criterion Decision Making) dengan menggabungkan seluruh data melalui bobot penilaian yang diperoleh dari hasil tes. Melalui metode electre ini diharapkan nantinya penelitian ini dapat membantu pihak sekolah dalam menentukan anak berprestasi tingkat autis.
\end{abstract}

Kata Kunci : SPK, Electre, Kriteria, Autis, Prestasi

\begin{abstract}
Ananda Karsa Mandiri Foundation Medan is an educational level that is intended for children with special needs $(A B K)$, has a very important role in developing children's personality through intelligence so that later they can be prepared to enter the next level of education. This autistic children's school is an educational institution specifically organized for students who enter the age between 6-12 years with exceptional intelligence and are available at primary and secondary education levels. Children with autism at the age of 6-12 years generally have problems in non-normative behavior that can be seen from the level of development that is experiencing difficulties in adjusting when studying (not concentrated) or in activities in the social environment both at school or at home. In order to know with certainty whether this autistic child can excel or not in his school, then there are certain criteria that need to be understood by educators in providing assessments covering all aspects through the use of electrical methods. Electre method is one of the methods by determining the order and generating decisions from various alternatives in MCDM (Multi Criterion Decision Making) by combining all data through the weight of the assessment obtained from the test results. Through this electre method it is hoped that this research will be able to assist the school in determining the autistic achievement of children.
\end{abstract}

Keywords: SPK, Electre, Criteria, Autism, Achievement 


\section{PENDAHULUAN}

Pendidikan

khusus

telah

memberikan secercah harapan bagi Anak Berkebutuhan Khusus (ABK) Autis sebab pendidikan telah mampu membentuk pola hidup mereka melalui pengembangan diri yang berkaitan dengan pengembangan jasmani maupun rohani, keterampilan, kecerdasan, perasaan, keinginan, sosial, juga keimanan. Dengan adanya pola ini, anak autis menjadi sempurna, mereka dapat meningkatkan hidupnya menjadi berbudaya dan bermoral. Yayasan Ananda Karsa Mandiri Medan merupakan sekolah yang telah memfasilitasi ABK autis dengan cara menghubungkan sistem kurikulum yang terdapat pada pendidikan umum dengan sistem pendidikan ABK yang terkenal dengan istilah sekolah inklusi.

Pemerintah telah menyediakan lembaga pendidikan bagi anak autis agar mereka mendapatkan layanan pendidikan yang sama seperti anak-anak normal pada umumnya, sesuai dengan pasal 15 UU No. 20 tahun 2003 tentang SISDIKNAS, menyatakan bahwa jenis pendidikan yang sesuai bagi anak berkebutuhan khusus yaitu melalui jalur Pendidikan Khusus. Sejalan dengan pasal 32 (1) UU No. 20 tahun 2003 telah memberikan batasan bahwa Pendidikan Khusus merupakan pendidikan bagi peserta didik yang memiliki tingkat kesulitan dalam mengikuti proses pembelajaran karena kelainan fisik, emosional, mental, sosial, dan/atau memiliki potensi kecerdasan dan bakat istimewa (Indonesia, 2003).

Strategi pendidikan yang berjalan selama ini umumnya memberikan perlakuan standar bagi Anak Berkebutuhan Khusus (ABK), sehingga diperlukan adanya perhatian lebih antar anak autis dalam kecakapan, minat, dan bakatnya agar potensi masing-masing anak autis dapat dikembangkan dan dikonversikan menjadi prestasi yang unggul.

Electre merupakan suatu metode untuk menentukan urutan dalam perangkingan melalui adanya perbandingan yang berpasangan antara Alternatif dan Kriteria yang sesuai atau prioritas dalam MCDM (Muliti Criterion Decision Making). Penggunaaan electre bertujuan untuk menentukan dan menghasilkan keputusan dari beberapa alternatif, dimana semua data akan digabungkan menjadi satu dengan bobot penilaian yang telah diperoleh melalui hasil tes penilaian (Tambunan, 2014).

\section{METODE PENELITIAN}

\section{Lokasi Penelitian}

Lokasi penelitian ditunjukkan pada Gambar 1 yaitu bertempat di Yayasan Ananda Karsa Mandiri - J1. Abdullah Lubis No.15 Medan, Sumatera Utara.

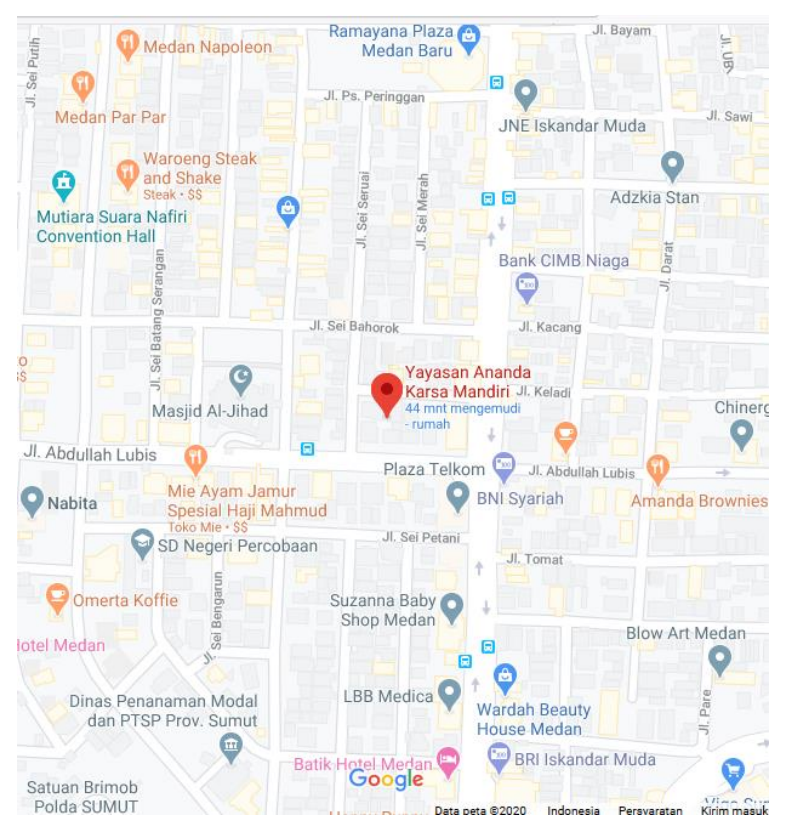


Gambar 1. Denah Lokasi Penelitian

\section{Prestasi Anak Autis Ditentukan Dari Kriteria}

Menurut (Yunita, Efendi, \& Sazaki, 2018) bahwa prestasi belajar sangat erat kaitannya dengan kegiatan belajar anak karena belajar adalah proses sedangkan prestasi adalah hasil dari proses pembelajaran tersebut. Prestasi belajar di bidang pendidikan merupakan hasil dari psikomotorik setelah proses pembelajaran selesai diikuti, kemudian akan diukur menggunakan instrumen tes atau yang sejenisnya.

Dalam pemilihan anak berprestasi tingkat autis ini dapat dilihat dari 5 kriteria penilaian yang telah ditentukan yaitu pengetahuan, pemahaman, sikap, keterampilan, kecakapan. Sehingga nantinya akan tercapai kompetensi lulusan dalam menentukan kenaikan kelas dan kelulusan bagi anak autis tersebut.

Penilaian yang diberikan bagi anak autis merupakan salah satu faktor penting untuk menentukan keberhasilan proses dan hasil belajar mereka. Anak autis yang bersekolah di sekolah inklusi memiliki hambatan belajar yang sangat beragam, oleh karena nya pendidik harus menyadari bahwa prestasi belajar yang mereka peroleh merupakan alat ukur keberhasilan proses pembelajaran.

\section{Sistem Pendukung Keputusan (Decision Making System)}

Sistem Pendukung Keputusan (SPK) adalah suatu pendekatan yang mendukung dalam pengambilan keputusan dengan menggunakan data, memberikan perangkat antarmuka yang mudah bagi pengguna serta dapat menggabungkan sebuah pemikiran dalam pengambilan keputusan (Arzoo, Prof, \& Rathod, 2017).

Sistem Pendukung Keputusan (SPK) merupakan salah satu cara dalam mengorganisir informasi yang dibutuhkan agar dapat digunakan dalam membuat keputusan (Sundari, Sinaga, Damanik, \& Wanto, 2019).

Menurut (Simangunsong \& Sinaga, 2019) bahwa sistem pendukung keputusan merupakan sistem yang telah dirancangdan dapat diterapkan dalam mendukung keputusan yang telah disepakati dalam pemilihan suatu objek.

\section{Electre (Elimination and Choice Translation Reality)}

Menurut Kumar dan Rathi (2014) Electre merupakan suatu metode yang digunakan dalam membantu pengambilan keputusan multi kriteria berdasarkan konsep perangkingan menggunakan perbandingan secara berpasangan dari alternatif ke alternatif secara berurut sesuai dengan kriteria yang telah ditentukan (Sundari et al., 2019). Metode electre berfungsi pada saat suatu kondisi dimana sebuah alternatif yang tidak sesuai akan dikeluarkan dan hanya mengambil alternatif yang dapat dibutuhkan.

Tahapan yang dilakukan untuk menyelesaikan permasalahan ini yaitu dengan menggunakan metode electre melalui beberapa tahapan berikut:

Tahap 1 Normalisasi Matriks Keputusan.

Tahapan ini berfungsi untuk mengubah tiap atribut menjadi nilai yang comparable. Berikut rumus dari tiap normalisasi yang dilakukan pada nilai $\mathrm{x}_{\mathrm{ij}}$ : 


$$
r_{i j}=\frac{x_{i j}}{\sqrt{\sum_{i=1}^{m} x_{i j}}}
$$

Matriks R hasil normalisasi:

$$
R=\left[\begin{array}{ccc}
r 11 & r 12 & r 1 n \\
r 21 & r 22 & r 2 n \\
r m 1 & r m 2 & r m n
\end{array}\right]
$$

Keterangan:

$\mathrm{R}=$ matriks yang dinormalisasi

$\mathrm{m}=$ alternatif

$\mathrm{n}=$ kriteria

$\mathrm{r}_{\mathrm{ij}}=$ normalisasi pengukuran pilihan dari alternatif $i$ ke kriteria $\mathrm{j}$ yang saling berkaitan

Tahap 2 Pembobotan Matriks yang di Normalisasi.

Pada tahapan ini, setiap kolom dari matriks $\mathrm{R}$ dikalikan dengan bobot-bobot $\left(\mathrm{w}_{\mathrm{j}}\right)$ yang telah ditentukan, maka $\mathrm{V}=\mathrm{RW}$ dapat dituliskan dalam rumus berikut:

$R=\left[\begin{array}{lll}v 11 & v 12 & v 1 n \\ v 21 & v 22 & v 2 n \\ v m 1 & v m 2 & v m n\end{array}\right]=\left[\begin{array}{ccc}w 1 r 11 & w 2 r 12 & w n r 1 n \\ w 1 r 21 & w 2 r 22 & w n r 2 n \\ w 1 r m 1 & w 2 r m 2 & w n r m n\end{array}\right]$

Tahap 3 Penentuan Matriks Concordance dan Discordance.

Tahapan ini berfungsi untuk membagi dua pasang subset yaitu concordance dan discordance dari alternatif $\mathrm{k}$ dan $1(\mathrm{k}, \mathrm{l}=1,2,3, \ldots, \mathrm{m}$ dan $\mathrm{k} \neq 1$ ) dengan kriteria $\mathrm{j}$.

concordance $=$ satu kriteria berada dalam suatu alternatif
$C_{k l}=\left\{j, y_{k j} \geq y_{l j}\right\}$, untuk $\mathrm{j}=$ $1,2,3, \ldots, \mathrm{n}$

discordance adalah komplementer dari concordance

$D_{k l}=\left\{j, y_{k j}<y_{l j}\right\}$, untuk $\mathrm{j}=$ $1,2,3, \ldots, \mathrm{n}$

Tahap 4 Hitung Matriks.

a) Concordance

Tahapan ini berfungsi untuk menentukan nilai dari setiap elemen yang terdapat pada matriks concordance dengan cara menjumlahkan bobotbobot yang termasuk dalam subset concordance.

Rumus:

$$
c_{k l}=\sum_{j c_{w}} w_{j}
$$

Hasil matriks concordance:

$$
c i j=\left[\begin{array}{ccccc}
c 11 & c 21 & c 31 & \cdots & c 1 n \\
c 21 & c 22 & c 23 & \cdots & c 2 n \\
c 31 & c 32 & c 33 & \cdots & c 3 n \\
\cdots & \cdots & \cdots & \cdots & \cdots \\
c m 1 & c m 2 & c m 3 & \cdots & c m n
\end{array}\right]
$$

\section{b) Discordance}

Tahapan ini berfungsi untuk menentukan nilai dari setiap elemen yang terdapat pada matriks discordance dengan membagi maksimum dari selisih nilai kriteria yang termasuk dalam subset discordance dengan selisih nilai dari seluruh kriteria yang ada. 
$d k l=\frac{\{\max (v m n-v m n-1 n)\} ; m, n \in D k l}{\{\max (v m n-v m n-1 n)\} ; m, n=1,2,3, \ldots}$

Hasil matriks discordance:

$$
d_{i j}=\left[\begin{array}{ccccc}
d_{11} & d_{21} & c 31 & \cdots & c_{1 n} \\
d_{21} & d_{22} & d_{23} & \cdots & d_{2 n} \\
d_{31} & d_{32} & d_{33} & \cdots & d_{3 n} \\
\cdots & \ldots & \cdots & \cdots & \cdots \\
d_{m 1} & d_{m 2} & d_{m 3} & \cdots & d_{m n}
\end{array}\right]
$$

Tahap 5 Penentuan Matriks Dominan.

a) Tahapan ini digunakan untuk membangun matriks dominan concordance dengan menggunakan bantuan nilai threshold yaitu dengan membandingkan nilai tiap elemen pada matriks concordance dengan nilai threshold nya.

$C_{i j} \geq \subseteq$

$c$ dengan nilai threshold $(\underline{c})$ :

$$
\mathrm{c}=\frac{\sum_{\mathrm{k}=1}^{\mathrm{n}} \sum_{\mathrm{l=1}}^{\mathrm{n}} \mathrm{c}_{\mathrm{kl}}}{\mathrm{m}^{*}(\mathrm{~m}-1)}
$$

Berikut ketentuan dari nilai setiap elemen yang terdapat pada matriks $F$ sebagai matriks dominan concordance:

$f_{k l}=1, j i k a_{c k l}{ }_{\underline{c}}$ dan $_{f_{k l}}=0, j i k a_{c k l}<\underline{c}$

b) Tahapan ini digunakan untuk membangun matriks dominan discordance yang juga menggunakan bantuan nilai threshold nya.

$$
\begin{array}{r}
G_{i j}=1 \text { jika } G_{i j} \geq \subseteq \\
0 \text { jika } G_{i j} \leq \subseteq
\end{array}
$$

$d$ dengan nilai threshold $(\underline{d})$ :

$$
d_{-}=\frac{\sum_{k=1}^{n} \sum_{l=1}^{n} d_{k l}}{m^{*}(m-1)}
$$

Berikut ketentuan dari nilai setiap elemen yang terdapat pada matriks $G$ sebagai matriks dominan discordance:

$$
g_{k l}=0, j i k a_{c k l} \geq \underset{-}{d d a n_{g_{k l}}=1, j i k a_{c k l}<d}
$$

Tahap 6 Penentuan Aggregate Dominance Matriks.

Tahapan ini digunakan sebagai matriks E, dimana setiap elemennya adalah perkalian antara elemen matriks $F$ dengan elemen matriks $\mathrm{G}$ :

$e_{k l}=f_{k l} x g_{k l}$

Tahap 7 Mengeluarkan Alternatif yang Tidak Diinginkan.

Tahapan ini digunakan sebagai matriks $\mathrm{E}$ yang memberikan urutan pilihan dari setiap alternatif, yaitu jika $e_{k l}=1$ maka alternatif $A_{k}$ menjadi pilihan terbaik dari $\mathrm{A}_{1}$. Dengan demikian baris pada matriks $\mathrm{E}$ yang memiliki jumlah $e_{k l}=1$ paling sedikit dapat dikeluarkan. Sehingga alternatif terbaik adalah yang mendominasi alternatif lainnya.

\section{HASIL PENELITIAN DAN}




\section{PEMBAHASAN}

Permasalahan utama yang sedang diteliti ini adalah bagaimana menerapkan metode electre sehingga dapat digunakan untuk membantu panitia ujian dalam menentukan anak berprestasi tingkat autis sesuai dengan kriteria - kriteria yang diinginkan oleh sekolah. Berdasarkan dari data yang diperoleh, maka dapat dilihat pada beberapa penilaian berikut:

\section{Menentukan Alternatif}

Nama-nama alternatif dapat dilihat pada Tabel 1.

Tabel 1. Alternatif

\begin{tabular}{|l|l|l|}
\hline KD & Nama Alternatif & Keterangan \\
\hline A1 & Andi Leo & Siswa Autis \\
\hline A2 & Lusiana & Siswa Autis \\
\hline A3 & Silvi Triana & Siswa Autis \\
\hline A4 & Dea Putri & Siswa Autis \\
\hline A5 & Joni Tan & Siswa Autis \\
\hline
\end{tabular}

2. Menentukan Kriteria dan Bobot

Tahapan ini membutuhkan kriteria yang akan dijadikan sebagai bahan perhitungan dalam menentukan anak berprestasi tingkat autis. Terdapat 5 kriteria yang akan digunakan dalam penelitian ini dengan inisial K1-K5. Pembobotan pada setiap kriteria merupakan langkah awal yang akan digunakan sebagai bahan pertimbangan antara tingkat kepentingan dari setiap kriteria.

Tabel 2. Kriteria dan Bobot yang Ditentukan

\begin{tabular}{c|c|c|c}
\hline Kriteria & Keterangan & Sym & Bobot \\
\hline
\end{tabular}

\begin{tabular}{l|l|c|c}
\hline K1 & Pengetahuan & PT & 5 \\
K2 & Pemahaman & PM & 4 \\
K3 & Sikap & SK & 3 \\
K4 & Keterampilan & KT & 2 \\
K5 & Kecakapan & KC & 1 \\
\hline \multicolumn{3}{c}{ Tingkat kepentingan } & Sangat \\
Buruk $(\mathrm{N}=1)$, Buruk $(\mathrm{N}=2), \quad$ Cukup \\
$(\mathrm{N}=3)$, Baik $(\mathrm{N}=4)$ dan Sangat Baik \\
$(\mathrm{N}=5) . \quad$ Pengambil keputusan akan \\
memberi bobot preferensi dari setiap \\
kriteria sebagai $\mathrm{w}=(5,4,3,2,1) . \quad$ Dapat \\
dilihat pada Tabel 2:
\end{tabular}

3. Perhitungan Metode Electre

Penelitian ini memiliki 5 kriteria dan 5 alternatif yang akan digunakan dalam perhitungan dengan metode electre yang disajikan pada Tabel 3:

Tabel 3. Data Nilai Peserta Ujian Anak Autis

\begin{tabular}{|l|c|c|c|c|c|}
\hline $\begin{array}{c}\text { Nama } \\
\text { Alternatif }\end{array}$ & PT & PM & SK & KT & KC \\
\hline Andi Leo & 80 & 100 & 20 & 100 & 80 \\
\hline Lusiana & 40 & 20 & 100 & 60 & 40 \\
\hline Silvi Triana & 100 & 80 & 80 & 40 & 40 \\
\hline Dea Putri & 60 & 60 & 60 & 40 & 40 \\
\hline Joni Tan & 60 & 80 & 80 & 20 & 60 \\
\hline
\end{tabular}

Tabel 4 menunjukkan nilai masingmasing alternatif (Ai) dari setiap kriteria prestasi $(\mathrm{Cj})$ yang telah ditentukan:

Tabel 4. Kecocokan antara Alternatif dengan Kriteria

\begin{tabular}{|c|c|l|}
\hline $\begin{array}{c}\text { Kriteria } \\
(\mathrm{Cj})\end{array}$ & $\begin{array}{c}\text { Bobot } \\
\text { Nilai }\end{array}$ & \multicolumn{1}{|c|}{ Keterangan } \\
\hline$\leq 35$ & 1 & Sangat Buruk \\
\hline $36-50$ & 2 & Buruk \\
\hline $51-70$ & 3 & Cukup \\
\hline $71-90$ & 4 & Baik \\
\hline
\end{tabular}




\begin{tabular}{|l|l|l|}
\hline$\geq 91$ & 5 & Sangat Baik \\
\hline
\end{tabular}

Berdasarkan data pada Tabel 4, maka dapat dilihat nilai dari calon anak berprestasi tingkat autis pada alternatif disetiap kriteria ditunjukkan pada Tabel 5.

Tabel 5. Tingkat Kecocokan Alternatif terhadap Kriteria

\begin{tabular}{l|c|c|c|c|c}
\hline \multicolumn{1}{c|}{$\begin{array}{c}\text { Nama } \\
\text { Alternatif }\end{array}$} & K1 & K2 & K3 & K4 & K5 \\
\hline Andi Leo & 4 & 5 & 1 & 5 & 4 \\
Lusiana & 2 & 1 & 5 & 3 & 2 \\
Silvi Triana & 5 & 4 & 4 & 2 & 2 \\
Dea Putri & 3 & 3 & 3 & 2 & 2 \\
Joni Tan & 3 & 4 & 4 & 1 & 3 \\
\hline
\end{tabular}

\section{Langkah 1}

Proses normalisasi matriks keputusan.

$$
\begin{aligned}
& r 11=\frac{x 11}{\sqrt{x_{11}^{2+} x_{21}^{2+} x_{31}^{2+} x_{41}{ }^{2+} x_{51}{ }^{2}}} \\
& r 11=\frac{4}{\sqrt{4^{2}+2^{2}+5^{2}+3^{2}+3^{2}}} \\
& r 11=\frac{4}{7,9372} \\
& r 11=0,5039
\end{aligned}
$$

Begitu seterusnya hingga diperoleh hasil matriks normalisasi yang disajikan pada Tabel 6.

Tabel 6. Hasil Matriks Normalisasi Keputusan

\begin{tabular}{|l|l|l|l|l|}
\hline 0,5039 & 0,7001 & 0,1222 & 0,7624 & 0,6963 \\
\hline 0,2519 & 0,1400 & 0,6108 & 0,4575 & 0,3481 \\
\hline 0,6299 & 0,5601 & 0,4887 & 0,3051 & 0,3481 \\
\hline 0,3779 & 0,4200 & 0,3665 & 0,3051 & 0,3481 \\
\hline 0,3779 & 0,5601 & 0,4887 & 0,1525 & 0,5222 \\
\hline
\end{tabular}

\section{Langkah 2}

Proses pembobotan pada matriks yang di normalisasi.

Langkah berikutnya, setiap kolom dari matriks $R$ dikalikan dengan bobot $(W j)$, dimana:

$$
\begin{aligned}
V_{11} & =R \times W \\
V_{11} & =0,5039 \times 5 \\
& =2,5195
\end{aligned}
$$

Begitu seterusnya hingga diperoleh hasil perkalian bobot preferensi dari setiap kriteria yang di normalisasi disajikan pada Tabel 7.

Tabel 7. Hasil Pembobotan Matriks yang di Normalisasi

\begin{tabular}{|l|l|l|l|l|}
\hline 2,5195 & 2,8004 & 0,3666 & 1,5248 & 0,6963 \\
\hline 1,2595 & 0,56 & 1,8324 & 0,915 & 0,3481 \\
\hline 3,1495 & 2,2404 & 1,4661 & 0,6102 & 0,3481 \\
\hline 1,8895 & 1,68 & 1,0995 & 0,6102 & 0,3481 \\
\hline 1,8895 & 2,2404 & 1,4661 & 0,305 & 0,5222 \\
\hline
\end{tabular}

\section{Langkah 3}

Proses penentuan matriks Concordance dan Discordance.

\section{a. Concordance}

$$
\begin{aligned}
& C_{k l}=\left\{j, y_{k j} \geq y_{l j}\right\}, \text { untuk } \mathrm{j}=1,2,3, \ldots, \mathrm{n} \\
& \begin{aligned}
C_{12} & =\{\mathrm{j}, \mathrm{v} 1 \mathrm{j} \geq \mathrm{v} 2 \mathrm{j}\}, \text { untuk } \mathrm{j}=1,2, \ldots, 5 \\
& =\{1,2,4,5\}
\end{aligned}
\end{aligned}
$$

Begitu seterusnya hingga diperoleh hasil Concordance dari nilai $w(5,4,3,2,1)$ disajikan pada Tabel 8 .

Tabel 8. Concordance

\begin{tabular}{|c|c|c|c|c|c|c|}
\hline \multirow{2}{*}{$\mathbf{C} \geq$} & \multicolumn{6}{|c|}{$\boldsymbol{k}$} \\
\cline { 3 - 7 } & \multicolumn{1}{|c|}{$\mathbf{v 1}$} & $\mathbf{v 2}$ & $\mathbf{v 3}$ & $\mathbf{v 4}$ & \multicolumn{1}{c|}{$\mathbf{v 5}$} \\
\hline \multirow{4}{*}{$\boldsymbol{l}$} & $\mathbf{v 1}$ & - & $1,2,4,5$ & 2,5 & 1,2 & $1,2,5$ \\
\cline { 2 - 7 } & $\mathbf{v 2}$ & 2,3 & - & 2,5 & 1,2 & 2 \\
\cline { 2 - 7 } & $\mathbf{v 3}$ & $1,3,4$ & $1,3,4,5$ & - & 1 & 1,5 \\
\hline
\end{tabular}




\begin{tabular}{|l|l|l|l|l|l|l|}
\hline v4 & $3,4,5$ & $3,4,5$ & $2,3,4,5$ & - & $3,4,5$ \\
\hline v5 & 3,4 & $1,3,4,5$ & $2,3,4$ & 1,2 & - \\
\hline
\end{tabular}

\begin{tabular}{|l|l|l|l|l|l|l|}
\hline $\mathbf{v 4}$ & 6 & 6 & 10 & - & 6 \\
\hline $\mathbf{v 5}$ & 5 & 11 & 9 & 9 & - \\
\hline
\end{tabular}

b. iscordance

$$
\begin{aligned}
D_{k l} & =\left\{j, y_{k j}<y_{l j}\right\}, \text { untuk } \mathrm{j}=1,2,3, \ldots, \mathrm{n} \\
D_{12} & =\{\mathrm{j}, \mathrm{v} 1 \mathrm{j}<\mathrm{v} 2 \mathrm{j}\}, \text { untuk } \mathrm{j}=1,2,3, \ldots, 5 \\
& =\{2,3\}
\end{aligned}
$$

Begitu seterusnya hingga diperoleh hasil Discordance dari nilai $w(5,4,3,2,1)$

\begin{tabular}{|c|c|c|c|c|c|c|}
\hline \multirow{2}{*}{\multicolumn{2}{|c|}{ D $<$}} & \multicolumn{5}{|c|}{$k$} \\
\hline & & v1 & v2 & v3 & $\mathrm{v4}$ & v5 \\
\hline \multirow{5}{*}{$l$} & v1 & - & 2,3 & $1,3,4$ & $3,4,5$ & 3,4 \\
\hline & v2 & $1,4,5$ & - & $1,3,4,5$ & $3,4,5$ & $1,3,4,5$ \\
\hline & v3 & 2,5 & 2 & - & $2,3,4,5$ & $2,3,4$ \\
\hline & v4 & 1,2 & 1,2 & 1 & - & 1,2 \\
\hline & v5 & 1,2 & 2 & 1,5 & $3,4,5$ & - \\
\hline
\end{tabular}
disajikan pada Tabel 9.

Tabel 9. Discordance

\section{Langkah 4}

Proses perhitungan matriks.

a. Concordance

$$
\begin{aligned}
& C_{k l}=\sum_{j c_{w}} w_{j} \\
& C_{1,2}=w_{2}+w_{3} \\
& C_{1,2}=4+3 \\
& C_{1,2}=7
\end{aligned}
$$

\begin{tabular}{|c|c|c|c|c|c|c|}
\hline \multirow{2}{*}{\multicolumn{2}{|c|}{$\mathrm{C}+$}} & \multicolumn{5}{|c|}{$\boldsymbol{k}$} \\
\hline & & v1 & v2 & v3 & v4 & v5 \\
\hline \multirow{3}{*}{$l$} & v1 & - & 12 & 5 & 9 & 10 \\
\hline & v2 & 7 & - & 5 & 9 & 4 \\
\hline & v3 & 10 & 11 & - & 5 & 6 \\
\hline
\end{tabular}

Begitu seterusnya hingga diperoleh hasil matriks Concordance dari nilai $w$ $(5,4,3,2,1)$ disajikan pada Tabel 10.

Tabel 10. Concordance

\section{b. Discordance}

$$
\begin{aligned}
& d k l=\frac{\{\max (v m n-v m n-1 n)\} ; m, n \in D k l}{\{\max (v m n-v m n-1 n)\} ; m, n=1,2,3, \ldots} \\
& d_{12}=\frac{\max \{|2,5195-1,2595| ;|1,5248-0,915|: \mid 0,6963-0,3481\}}{\max \{|2,5195-1,2595| ;|2,8004-0,56| ;|0,3666-1,8324| ; 1,5248-0,915|;| 0,6963-0,3481 \mid\}} \\
& d_{12}=\frac{\max \{|1,26| ;|0,6098| ; \mid 0,3482\}}{\max \{|1,26| ;|2,2404| ;|-1,4658| ;|0,6098| ;|0,3482|\}} \\
& d_{12}=\frac{1,26}{2,2404} \\
& d_{12}=0,5624
\end{aligned}
$$

Begitu seterusnya hingga diperoleh hasil matriks Discordance dari nilai $w$ $(5,4,3,2,1)$ disajikan pada Tabel 11.

Tabel 11. Discordance

\begin{tabular}{|c|c|l|l|l|l|l|}
\hline \multirow{2}{*}{$\mathbf{D}_{\text {(max) }}$} & \multicolumn{6}{|c|}{$k$} \\
\cline { 3 - 8 } & \multicolumn{1}{|c|}{$\mathbf{v 1}$} & \multicolumn{1}{c|}{$\mathbf{v 2}$} & \multicolumn{1}{c|}{$\mathbf{v 3}$} & $\mathbf{v 4}$ & \multicolumn{1}{c|}{$\mathbf{5}$} \\
\hline \multirow{4}{*}{$\boldsymbol{l}$} & $\mathbf{v 1}$ & - & 1 & 1 & 1 & 1 \\
\cline { 2 - 8 } & $\mathbf{v 2}$ & 0,5624 & - & 1 & 0 & 0,3749 \\
\cline { 2 - 7 } & $\mathbf{v 3}$ & 0,6122 & 0 & - & 0 & 0 \\
\cline { 2 - 7 } & $\mathbf{v 4}$ & 1 & 0,4159 & 1 & - & 1 \\
\cline { 2 - 7 } & $\mathbf{v 5}$ & 0,5165 & 0 & 1 & 1 & - \\
\hline
\end{tabular}

\section{Langkah 5}

Proses menentukan matriks dominan.

a. Concordance

$$
\mathrm{c}=\frac{\sum_{\mathrm{k}=1}^{\mathrm{n}} \sum_{\mathrm{l=1}}^{\mathrm{n}} \mathrm{c}_{\mathrm{kl}}}{\mathrm{m}^{*}(\mathrm{~m}-1)}
$$

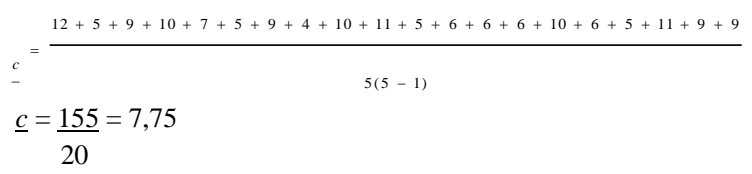

Nilai Threshold ( $\underline{c}$ ) yang diperoleh dapat dilihat pada Tabel 12 .

Tabel 12. Matriks Dominan Concordance

\begin{tabular}{|c|c|c|c|c|c|c|}
\hline \multicolumn{2}{|c|}{ F } & \multicolumn{5}{c|}{$k$} \\
\cline { 3 - 7 } & & $\mathbf{v 1}$ & $\mathbf{v 2}$ & $\mathbf{v 3}$ & $\mathbf{v 4}$ & $\mathbf{v 5}$ \\
\hline \multirow{2}{*}{$\boldsymbol{l} l$} & $\mathbf{v 1}$ & - & 1 & 0 & 0 & 0 \\
\cline { 2 - 7 } & \multirow{2}{*}{$\mathbf{v 2}$} & 0 & - & 0 & 0 & 0 \\
\hline
\end{tabular}




\begin{tabular}{|c|c|c|c|c|c|c|}
\hline & $\mathbf{v 3}$ & 0 & 1 & - & 0 & 0 \\
\cline { 2 - 7 } & $\mathbf{v 4}$ & 0 & 0 & 0 & - & 0 \\
\cline { 2 - 7 } & $\mathbf{v 5}$ & 0 & 1 & 0 & 0 & - \\
\hline
\end{tabular}

b. Discordance

$$
d=\frac{\sum_{k=1}^{n} \sum_{l=1}^{n} d_{k l}}{m^{*}(m-1)}
$$

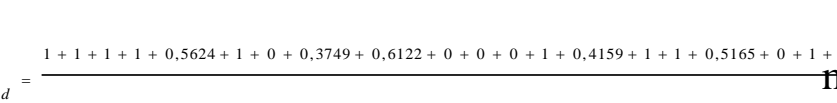
$\underline{d}=\underline{12,4819}=0,624$

Nilai Threshold ( $\underline{d}$ ) yang diperoleh dapat dilihat pada Tabel 13.

Tabel 13. Matriks Dominan Discordance

\begin{tabular}{|c|c|c|c|c|c|c|}
\hline \multicolumn{2}{|c|}{ G } & \multicolumn{5}{|c|}{$\boldsymbol{k}$} \\
\cline { 3 - 8 } & $\mathbf{v 1}$ & - & $\mathbf{v}$ & $\mathbf{v 3}$ & $\mathbf{v 4}$ & $\mathbf{v 5}$ \\
\hline \multirow{4}{*}{$\boldsymbol{l}$} & $\mathbf{v 1}$ & - & 1 & 1 & 1 & 1 \\
\cline { 2 - 7 } & $\mathbf{v 2}$ & 0 & - & 1 & 0 & 0 \\
\cline { 2 - 7 } & $\mathbf{v 3}$ & 1 & 0 & - & 0 & 0 \\
\cline { 2 - 7 } & $\mathbf{v 4}$ & 1 & 0 & 1 & - & 1 \\
\cline { 2 - 7 } & $\mathbf{v 5}$ & 0 & 0 & 1 & 1 & - \\
\hline
\end{tabular}

\section{Langkah 6}

Proses menentukan aggregate dominance matriks $E$.

$e_{k l}=f_{k l} x g_{k l}$

$E_{12}=F_{12} \times G_{12}=1 \times 1=1$

Begitu seterusnya hingga di peroleh hasil matriks E pada Tabel 14.

Tabel 14. Matriks Aggregate Dominance

\begin{tabular}{|c|c|c|c|c|c|c|}
\hline \multicolumn{2}{|c|}{ E } & \multicolumn{5}{|c|}{$k$} \\
\cline { 3 - 7 } \multicolumn{2}{|c|}{$l$} & v1 & v2 & v3 & v4 & v5 \\
\hline \multirow{3}{*}{$l$} & v1 & - & 1 & 0 & 0 & 0 \\
\cline { 2 - 7 } & v2 & 0 & - & 0 & 0 & 0 \\
\cline { 2 - 7 } & \multirow{2}{*}{ v3 } & 0 & 0 & - & 0 & 0 \\
\hline
\end{tabular}

\begin{tabular}{|c|c|c|c|c|c|c|}
\hline & $\mathbf{v 4}$ & 0 & 0 & 0 & - & 0 \\
\cline { 2 - 7 } & $\mathbf{v 5}$ & 0 & 0 & 0 & 0 & - \\
\hline
\end{tabular}

\section{Langkah 7}

Proses mengeluarkan alternatif yang tidak diinginkan.

Langkah selanjutnya yaitu mengeluarkan alternatif yang tidak diinginkan, jika $e_{k l}=1$ maka alternatif $\mathrm{A}_{\mathrm{k}}$ menjadi pilihan terbaik dari $A_{1}$. Dengan demikian, baris pada matriks $\mathrm{E}$ yang memiliki jumlah ekl=1 paling sedikit dapat dikeluarkan.

Dari hasil perhitungan yang diperoleh menggunakan metode electre ini, maka pengambil keputusan mengeluarkan baris kedua, ketiga, keempat, dan kelima, sehingga tersisa baris kesatu sebagai peringkat tertinggi untuk anak berprestasi tingkat autis yaitu Andi Leo dengan perolehan nilai $\mathrm{E} 12=1$ yang terdapat pada posisi alternatif $\mathrm{A}_{1}$.

\section{KESIMPULAN DAN SARAN}

Dari penelitian ini, maka penulis menyimpulkan bahwa metode electre merupakan metode yang tepat digunakan dalam penentuan urutan prioritas terbaik. Dimana, urutan tersebut dipengaruhi oleh jenis preferensi yang digunakan dengan membandingkan nilai alternatifnya, maka diperoleh urutan alternatif terbaik dengan hasil yang objektif. Sehingga dari penelitian ini, penulis mengusulkan Andi Leo sebagai salah satu anak berprestasi tingkat autis di Yayasan Ananda Karsa Mandiri Medan.

Hasil penelitian ini diharapkan nantinya dapat membantu para pengambil keputusan, terkait permasalahan ini, untuk 
dapat menentukan siswa berprestasi di sekolahnya.

\section{DAFTAR PUSTAKA}

Arzoo, M. K., Prof, A., \& Rathod, K. (2017). K-Means algorithm with different distance metrics in spatial data mining with uses of NetBeans IDE 8. 2. Int. Res. J. Eng. Technol, 4(4), 2363-2368.

Indonesia, P. R. (2003). Undang-undang Republik Indonesia nomor 20 tahun 2003 tentang sistem pendidikan nasional. Jakarta: Pemerintah Republik Indonesia.

Simangunsong, P. B. N., \& Sinaga, S. B. (2019). Sistem Pendukung Keputusan Pemilihan Dosen Berprestasi. Yayasan Kita Menulis.

Sundari, S., Sinaga, S. M., Damanik, I. S., \& Wanto, A. (2019). Sistem Pendukung Keputusan Pemilihan Peserta Olimpiade Matematika SMA Swasta Teladan Pematangsiantar Dengan Metode Electre. Seminar Nasional Teknologi Komputer \& Sains (SAINTEKS), 1(1).

Tambunan, H. A. (2014). Sistem Pendukung Keputusan Pemilihan Siswa Berprestasi Dengan Metode Electre. Vol, 7, 131-135.

Yunita, Y., Efendi, R., \& Sazaki, Y. (2018). Group Decision Support System (GDSS) Menggunakan Metode Electre dan Copeland Score dalam Menentukan Siswa Berprestasi. Teknomatika, 8(2). 